\title{
First meeting of Editors of Europhysics Journals
}

\section{J. de Boer}

Executive Committee feels that a Council meeting should be held prior to that time to discuss thoroughly all the elements involved. It requests a meeting of the Council on 20,21 October 1970 in Budapest.

With respect to membership fees from the National Societies, Academies, Groups and Laboratories (i.e. Ordinary Members category $4 b$ ), we give in the table above a survey of data for 1970 . From this we see that the annual fee from a National Society etc. varies between $1.59 \mathrm{Sw}$. frs and $4.50 \mathrm{Sw}$. frs per society member, the largest societies paying the smallest amounts per society member, as a result of the sliding-scale procedure. On the other hand, it would cleary be wrong to take these figures as the sole measure of the involvement of a National Society in the affairs of the European Physical Society. Through participation in the Executive Committee, Advisory Committees, Divisional Boards and the Council itself, they actively contribute to the development of the EPS.

The Executive Committee is equally aware of the necessity for increased efforts to ensure that the National Societies and Academies consider the EPS as an integral part of their own preoccupation with physics. One such step was mentioned in the foregoing article - the active participation of member societies in the editorial work of Europhysics News. This is also a way of demonstrating that the member societies are actually involved in the affairs of the EPS... not only in paying membership fees. The EPS concerns all European physicists.

The Publication Committee meeting on 22 May together with the Editors of Europhysics Journals.
The Publication Committee met on 22 May together with Editors of the Europhysics Journals. This was the first of a series of meetings which will take place at regular intervals to discuss general problems concerning the scientific policy of the Europhysics Journals.

One of the main concerns of these meetings will be to discuss the refereeing system, since this is considered to be one of the most essential requirements for good quality scientific journals. The general questions about the refereeing system, which have been put to the editorial boards of the Europhysics Journals, concern the choice and the number of referees for each paper, the percentage of rejected or modified articles, the anonimity of the referees, the question as to whether the advice of the referees is always followed, and general questions of procedure for review articles, letters and notes.

A second point which is considered to be of much importance is that concerning the relations existing between the smaller group of editors and the larger editorial board, or advisory board, of the various journals. The general view of the Publication Committee is that these larger editorial boards should take an active part in determining or influencing the editorial policy of the journals.

At the meeting on 22 May a first draft of the Europhysics Style Manual was discussed in detail. The items which are covered by the first draft concern: general remarks about the material to be submitted, the general presentation and the title page, the form of the abstracts, the writing of formulae, illustrations and tables, and the presentation of references and footnotes. As regards symbols it was decided that authors will be encouraged to follow the recommendations of the International Union of Pure and Applied Physics, contained in the Document U.I.P.11 S.U.N.65-3 (1965) which will be included as an appendix to the Style Manual.

A separate discussion took place about the system to be used for references. The majority seemed to be in favour of the order indicated in the ISO-Recommendation R 690 , adopted in 1968, for bibliographical references.

Further discussion took place on the indexing system to be used both in connection with the contents at the end of the volume and the indexing of the articles separately. It was decided that the indexing system of Physics Abstracts will be followed and that a closer study will be made of the form which this can be made available in the Style Manual.

Finally, it was decided that the next meeting of the Publication Committee together with the Editors of the Europhysics Journals will be held, most probably in Paris, on 12,13 November, 1970. At this meeting a thorough discussion of the refereeing system and the editorial direction of the journals will take place and a new draft for the Style Manual, taking into account the remarks from the first meeting, will then be submitted for approval.

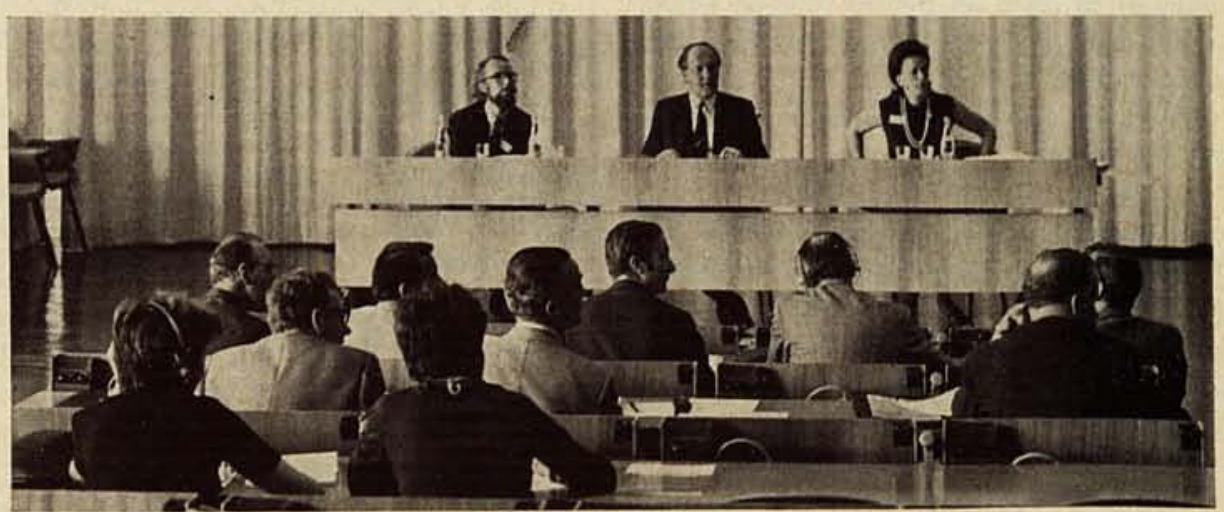

